\title{
CONCLUSIONES
}

\section{CONCLUSIONES DEL TALLER RESULTADOS Y LECCIONES APRENDIDAS EN LA PANDEMIA DE GRIPE A (H1N1) 2009 A PARTIR DE LOS PROYECTOS DE INVESTIGACIÓN Y LA VIGILANCIA DE LA SALUD PÚBLICA}

Pere Godoy en nombre de ponentes y moderadores del taller del CIBER de Epidemiología y Salud Pública sobre gripe pandémica A (H1N1) 2009.

Ponentes: Tomas Pumarola, María José Sierra, Pere Godoy, Núria Torner, Francesc Calafell, Àngela Domínguez, Jesús Castilla, Manel Nebot, Hernán Vargas, Fernando G Benavides, Jordi Alonso y Amparo Larrauri.

Moderadores: Odorina Tello, Neus Camps, Carmen Cabezas, Joan Caylà, Anna Rodés y Jordi Delclos

El día 1 de octubre de 2010, el CIBER de Epidemiología y Salud Pública realizó en Barcelona, un taller sobre la pandemia de gripe gripe (H1N1) 2009 para revisar los resultados preliminares de los proyectos de investigación y los estudios de vigilancia epidemiológica y en el cual se alcanzaron las siguientes conclusiones:

Se considera que la actividad pandémica ha sido de intensidad moderada y temprana en el tiempo, con mayor afectación relativa en niños y jóvenes y menor en los mayores de 64 años.

La onda pandémica de otoño 2009 presentó un carácter leve teniendo en cuenta tasas de letalidad, si bien se observó un desplazamiento de las defunciones confirmadas por el virus pandémico a edades más jóvenes.

La vigilancia de casos graves sugiere un nivel de gravedad moderado y similar al observado en el hemisferio sur.

Se recomienda introducir la vigilancia de casos graves hospitalizados para valorar el impacto que tiene la gripe estacional y tener referentes históricos.
Se ha observado un predominio absoluto del virus gripal A (H1N1) 2009 durante la onda pandémica de la temporada 20092010.

Se destaca la importancia de los laboratorios de referencia para implementar nuevas técnicas para caracterizar los virus circulantes (mutaciones, resistencias y factores de virulencia).

La existencia de un Plan de Preparación y Respuesta, con estructuras definidas de funcionamiento y protocolos previos, permitió una respuesta rápida y coordinada.

La alerta de la gripe pandémica ha puesto de manifiesto la fortaleza del sistema de vigilancia, pero se considera que se debería mejorar la capacidad de movilizar recursos y reducir el voluntarismo.

Se debe seguir con la promoción de medidas preventivas y de higiene que se ha llevado a cabo para el control de la transmisión de la gripe y otros virus respiratorios.

La información a la población y a los profesionales sanitarios no siempre ha llegado de forma adecuada. Se considera fundamental la colaboración de las instituciones de investi- 
gación con las de Salud Pública para implementar proyectos de investigación sobre problemas que ocasionan o puedan ocasionar alertas y crisis de salud pública.

La vacuna pandémica presentó un alta efectividad para prevenir casos de gripe A (H1N1) 2009, tanto ambulatorios como hospitalizados.

Existió una baja percepción de la eficacia y la seguridad de la vacuna contra la gripe A (H1N1) 2009

La disponibilidad tardía de la vacuna y la baja cobertura en poblaciones de riesgo limitaron su potencial impacto en la prevención de casos y hospitalizaciones.

Se recomienda aprovechar otras bases de datos ya existentes para medir el impacto de la gripe en términos de costes laborales, sociales y económicos.

Los estudios que proporcionan estimaciones actuales y directas sobre la utilización de recursos socio-sanitarios en pacientes con gripe, son necesarios para poder evaluar el impacto de la misma.

Los costes más elevados se deben a la hospitalización y la incapacidad temporal por enfermedad.

Se ha observado un impacto notable en la dinámica escolar (absentismo de alumnos y profesores), aunque una proporción elevada (pero $<85 \%$ ) de centros adoptaron las medidas recomendadas.

La información que han recibido los centros escolares de la administración ha sido bien valorada.

Existen factores asociados a la adopción de medidas preventivas, como disrupción social, impacto económico en las familias y empresas, que se deben tener en cuenta para mejorar los programas de prevención.

Se considera poco probable un aumento de la transmisión en el próximo invierno debido a:

- Inmunidad natural en personas de edad avanzada, por exposición a cepas antigénicamente similares

- Inmunidad adquirida en la población por exposición durante la temporada pandémica 2009-2010

- Campañas de vacunación.

Se esperan niveles de actividad gripal propios de un período interpandémico, con una cocirculación de virus gripales $\mathrm{A}(\mathrm{H} 1 \mathrm{~N} 1)$ 2009, A(H3N2) y B. 